\title{
Peculiarities of refractive index dispersion of TGS crystals
}

\author{
O.Ya.Myshchyshyn, B.V.Andriyevsky, M.O.Romanyuk, \\ V.Yu.Kurlyak \\ The Ivan Franko State University of Lviv, \\ 8 Kyryla i Mefodiya Str., 79005 Lviv, Ukraine
}

Received September 9, 1998, in final form September 15, 1999

\begin{abstract}
Based on solving the Kramers-Kronig integral equation, binding the spectrum of refractive index $n(\omega)$ of dielectric experimentally measured in the range of transparency $(\omega)$ and its spectrum of absorption index $\mathrm{k}\left(\omega^{\prime}\right)$ in the fundamental range $\left(\omega^{\prime}\right)$, the dispersion analysis of these parameters has been proposed. The elaborated method has been applied to the triglycine sulphate crystal, in which the display of valence electrons interaction has been established, and the temperature dependence of the characteristic parameter of this interaction has been studied in the region including the ferroelectric phase transition at $T_{\mathrm{c}}=49^{\circ} \mathrm{C}$.
\end{abstract}

Key words: ferroelectrics, optical properties, dispersion of refractive index

PACS: $77.80 . \mathrm{Bh}, 77.84 . \mathrm{Fa}, 78.20 . \mathrm{Ci}$

\section{Introduction}

The photon energy dispersion of the refractive index $n(\omega)$ of a dielectric such as the triglycine sulphate crystal (TGS) in the range of its transparency $(0.4-5.6 \mathrm{eV})$ is determined by the spectrum of absorption index $\mathrm{k}\left(\omega^{\prime}\right)$ in the range of resonance excitation of valence electrons $\left(\omega^{\prime}>5.6 \mathrm{eV}\right.$ for TGS) according to the known KramersKronig relation [1]

$$
n(\omega)-1=\frac{2}{\pi} \int_{0}^{\infty} \frac{\omega^{\prime} k\left(\omega^{\prime}\right) \mathrm{d} \omega^{\prime}}{\omega^{\prime 2}-\omega^{2}} .
$$

In the previous papers $[2,3]$ the method of solving the integral equation (IE) (1) had been offered. In the present paper the method of IE (1) solving has been presented in detail. This method has been applied to the ferroelectric triglycine sulphate (TGS) crystal for the sake of studying the peculiarities of dispersion of refractive index $\mathrm{n}(\omega)$ and its temperature changes in the range of phase transition at $T_{\mathrm{c}}=49{ }^{\circ} \mathrm{C}$. 


\section{Method of investigation} $[4]$

Kramers-Kronig relationship (1) is a partial case of the first order Fredholm IE

$$
\int_{a}^{b} R(x, s) k(s)=f(x) c \leqslant x \leqslant d
$$

Here $R(x, s)$ is the kernel of equation, $f(x)$ is the right hand known part determined on $[c d]$ range, $k(s)$ is the unknown function determined on $[a b]$ range. The relation $[a b] \neq[c d]$ takes place. IE (1) can be presented as follows:

$$
n(\omega)-1=\frac{2}{\pi} \int_{0}^{\omega_{3}} \frac{\omega^{\prime} k\left(\omega^{\prime}\right) \mathrm{d} \omega^{\prime}}{\omega^{\prime 2}-\omega^{2}}+\frac{2}{\pi} \int_{\omega_{3}}^{\infty} \frac{\omega^{\prime} k\left(\omega^{\prime}\right) \mathrm{d} \omega^{\prime}}{\omega^{\prime 2}-\omega^{2}}=I_{1}+I_{2}
$$

where $\omega_{3}$ has been stated as $\omega_{3}=50 \mathrm{eV}$. The latter value of photon energy exhausts the optical transitions of valence electrons to the lowest conduction band, which almost completely form the refractive index dispersion $n(\omega)$ in any dielectric. In the $\omega^{\prime}>50 \mathrm{eV}$ range the absorption index $k\left(\omega^{\prime}\right)$ was approximated by the dependence $k\left(\omega^{\prime}\right) \sim\left(\omega^{\prime}\right)^{-7 / 2}$ with the power $\mathrm{p}=-7 / 2[5]$. Taking into account the latter fact and the relation $\omega^{2} \ll \omega^{\prime 2}\left(\omega^{\prime}>\omega^{3}\right)$, one can calculate the integral $I_{2}$ analytically using the iteration method [2]. Then the problem is transformed to solving the next IE

$$
n^{\prime}(\omega)-1=n(\omega)-1-I_{2}=\frac{2}{\pi} \int_{0}^{\omega_{1}} \frac{\omega^{\prime} k\left(\omega^{\prime}\right) \mathrm{d} \omega^{\prime}}{\omega^{\prime 2}-\omega^{2}}+\frac{2}{\pi} \int_{\omega_{2}}^{\omega_{3}} \frac{\omega^{\prime} k\left(\omega^{\prime}\right) \mathrm{d} \omega^{\prime}}{\omega^{\prime 2}-\omega^{2}}=I_{1} .
$$

The first integral in (4) reflects the part of $n(\omega)$ value to be formed by the vibration (phonon) subsystem of a dielectric while the second integral to be formed by the electron subsystem. The contribution to the $n(\omega)$ from the electron subsystem of dielectric predominates over the analogous contribution from the vibration subsystem, because the electron spectrum width $\omega_{3}-\omega_{2} \sim 40 \mathrm{eV}$ is much greater than the vibration spectrum width $\omega_{1}-0 \sim 0.4 \mathrm{eV}$ and the corresponding absorption index values are of the same order. The fundamental absorption band in the range of vibration excitations is represented in the work by one oscillator $\omega=0.2 \mathrm{eV}$ corresponding to the center of the typical vibration band $0-0.4 \mathrm{eV}$.

IE (4) can be represented in the form of a system of $N$ linear algebraic equations. This system can be solved by the least square fitting method [6], in which the greatest rank of characteristic matrix should be chosen to obtain the positive $k_{i}$ values. This is the only necessary condition for applying this method to different mathematical problems of the type (2). From this viewpoint, this method can be applied to the equation (2) with unrestricted forms of the kernel $\mathrm{R}(\mathrm{x}, \mathrm{s})$. One can use the calculated spectrum $k\left(\omega^{\prime}\right)$ to find the adequate dispersion $n_{\mathrm{c}}(\omega)$ through the formula (4) and then to find the discrepancy $\delta n(\omega)=n_{\mathrm{c}}(\omega)-n(\omega)$ for the experimental $(n(\omega))$ and re-calculated $\left(n_{\mathrm{c}}(\omega)\right)$ spectra. Among the reasons of this discrepancy are the errors 
in experimental determining the $n(\omega)$ dispersion. The validity of the method was checked using the following test. First, the known $k_{i}\left(\omega^{\prime}\right)$ spectrum of hypothetical material in the $\omega^{\prime}>5.0 \mathrm{eV}$ range was used to calculate the dispersion $n(\omega)$ in the 0.4-5.0 eV range from the relation (4). Then, the corresponding absorption $k\left(\omega^{\prime}\right)$ spectrum was calculated by solving the same IE (4). One can estimate the degree of $k_{i}\left(\omega^{\prime}\right)$ spectrum reproducibility from the figure 1. Even a relatively narrow spectral band is well reproduced if it is placed sufficiently close to the low-energy edge of the fundamental absorption range.

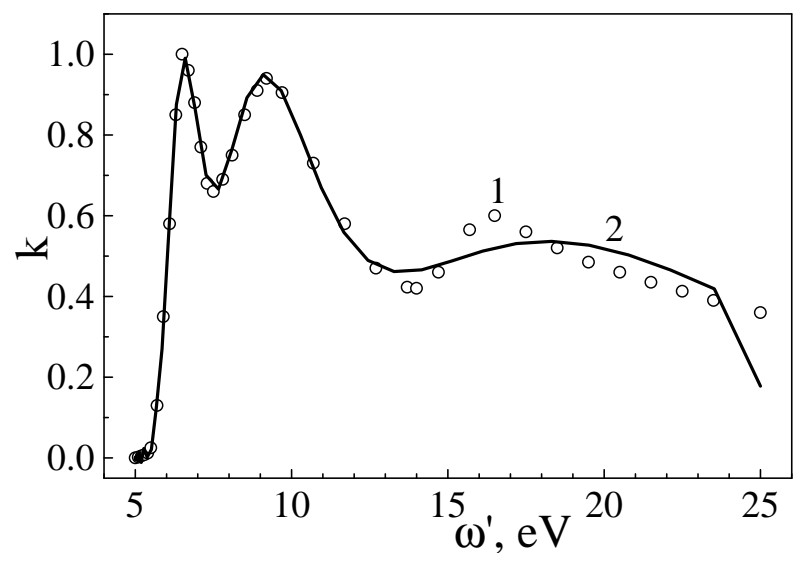

Figure 1. Absorption index spectra $k\left(\omega^{\prime}\right)$ of hypothetical material: open circles - input data; solid line - calculated data.

\section{Results and discussion}

Two absorption spectra $k\left(\omega^{\prime}\right)$ for TGS crystal are shown in figure 2. The spectra have been obtained using two different methods: from the calculation by the experimental reflection spectra $R\left(\omega^{\prime}\right)$ in the $5-22 \mathrm{eV}$ range (1) [7] and from the calculation by the refractive index dispersion $n(\omega)$ in the 1.5-5.2 eV range (2) [8]. Both spectra are similar. Small energy region $\Delta \omega^{\prime} \sim 1 \mathrm{eV}$ with negative $k\left(\omega^{\prime}\right)$ values is observed in the low-energy range of the spectrum 2 . An analysis of the solutions of the IE (4) for different analytical dependences $k\left(\omega^{\prime}\right) \sim \omega^{\prime(-p)}$ in the $\omega^{\prime}>\omega_{3}$ range (different values of the power $\mathrm{p}$ ) has shown that one should find the cause of negative $k\left(\omega^{\prime}\right)$ values in other physical mechanisms of refractive index dispersion $n(\omega)$ formation not taken into consideration in the equation (4). There are at least two mechanisms of the kind.

First, the damping of electron excitations can be presented in the following form of the kernel of IE (2) [9].

$$
R\left(\omega^{\prime}, \omega\right)=\frac{2 \omega^{\prime}}{\pi\left(\omega^{\prime 2}-\omega^{2}+\frac{\gamma^{2} \omega^{2}}{\omega^{\prime 2}-\omega^{2}}\right)} .
$$




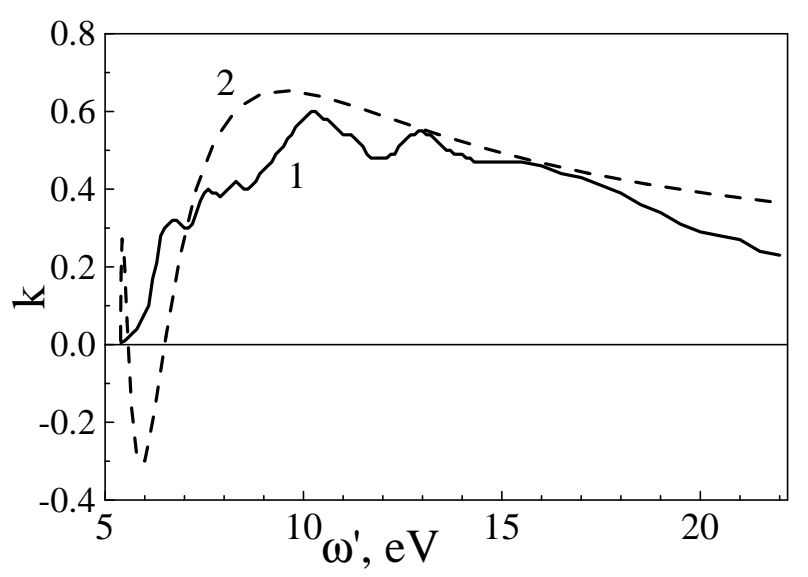

Figure 2. Absorption spectra $k\left(\omega^{\prime}\right)$ of TGS crystal at $25{ }^{\circ} \mathrm{C}: 1$ - obtained from experimental reflection spectra; 2 - calculated from the IE (4)

Here, $\gamma$ is a characteristic energy (effective half-width of fundamental band for the dielectric), to be inversely proportional to the damping time $\tau$ of electron excitations $(\tau \sim h / \gamma)$.

Second, a spatial dispersion, which can be displayed at high energies of refractive index dispersion, is not accounted for in the IEs (1) and (4) either. A spatial dispersion is the dependence of polarization of the dielectric on the wavelength vector $q[10,11]$. That can be displayed on the refractive index dispersion $n(\omega)$, because the wavelength vector $q$ is connected by means of frequency $\nu$ with the energy $\omega$ $:|q|=2 \pi / \lambda=2 \pi n \nu / c=n \omega / h c$. Spatial dispersion effects are essential close to the exciton resonance regions, and its value can be characterized by the effective mass of exciton $M_{\text {eff }}$ [10]. Taking into account this effect, the kernel of the IE (2) can be presented in the form [11]

$$
R\left(E, E_{0}\right)=\frac{2 E}{\pi\left(E^{2}-E_{0}^{2}+\frac{E E_{0}^{2}}{M_{\mathrm{eff}} c^{2}}\right)},
$$

where $c$ is the light velocity in vacuum. Both corrections in the kernels (5) and (6) decrease the refractive indices $n(\omega)$ and are inversely proportional to the $\left(\omega^{\prime 2}-\omega^{2}\right)$ difference. Ignoring this peculiarity can be the cause of negative absorption index values observed at the low-energy region of fundamental absorption spectrum $k\left(\omega^{\prime}\right)$ (figure 2).

Applying the kernels (5) and (6) to the absorption index calculations for TGS crystal has shown the necessity of comparatively considerable corrections for the kernel of IE (4) to avoid negative values in the $k\left(\omega^{\prime}\right)$ spectrum. These are comparatively large effective half-width, $\gamma \sim 5 \mathrm{eV}$, or comparatively small mass $M_{\text {eff }}=510^{-4} m_{\mathrm{e}}$. The above mentioned corrections of the kernel of IE (4) lead to an essential decrease of the discrepancy $\delta n(\omega)=n_{\mathrm{c}}(\omega)-n(\omega)$ of the calculated and the experimental refractive index dispersions. The decrease of this discrepancy is $200-300 \%$ of the value corresponding to the not changed kernel of the IE (4) (figure 3). 
The parameters $\gamma$ or $M_{\text {eff }}$ probably depend upon the energy $\omega^{\prime}$ in wide spectral range $5-50 \mathrm{eV}$. The curves 2 in figure 3 and figure 4 correspond to the smoothed dependence of the effective mass, $M_{\text {eff }}=$ const $\cdot \omega^{\prime} / \omega$, for which the only positive values $k\left(\omega^{\prime}\right)$ and sharp exciton-like maximum on the low-energy edge are observed (figure 4). The presence of excitons in this region of TGS fundamental absorption had been shown earlier [12]. The spatial dispersion can be interpreted as the presence of elastic bonds between spatially separated electron oscillators [11]. On the other hand, the damping of electron excitations in the crystal is realized due to some bonds of the active oscillator with the surrounding particles. Thus, both of the above mentioned mechanisms can reflect a common physical feature. This is the presence of the bonds between elementary oscillators (particles) in the characteristic range of the valence electron localization $\left(\sim 10^{2} \mathrm{~nm}\right)$. So far as the temperature determined phase transitions in crystalline dielectrics are considered to be of cooperative effect, then investigating the temperature dependence of spatial dispersion $M_{\text {eff }}(T)$ or the damping parameters $\gamma(T)$ can be useful for studying these critical phenomena.

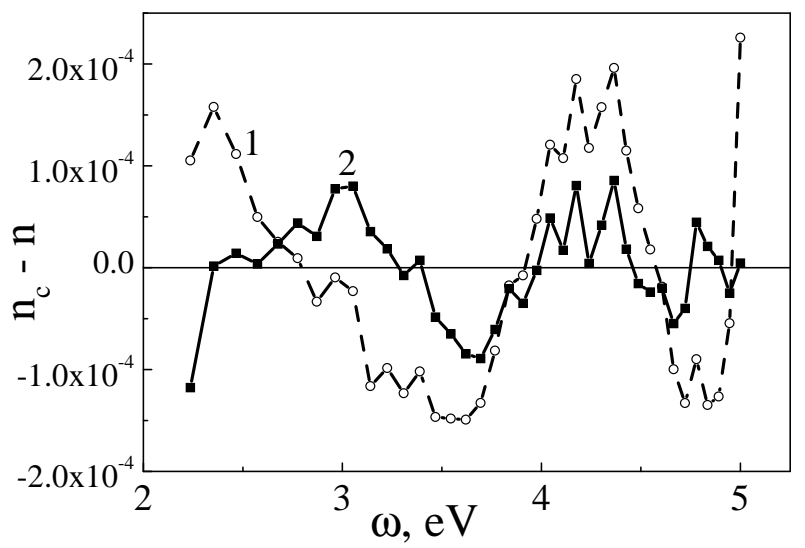

Figure 3. Spectral dependences of the discrepancy $\delta n(\omega)=n_{\mathrm{c}}(\omega)-n(\omega): 1-$ $n_{\mathrm{c}}(\omega)$ is calculated from the equation (4); $2-n_{\mathrm{c}}(\omega)$ is calculated from the IE (4) with the kernel (6)

Based on the refractive index $n(\omega)$ of TGS crystal, which had been measured at 13 temperature points in the $0-79{ }^{\circ} \mathrm{C}$ region [8], the temperature dependence of an effective exciton mass $M_{\text {eff }}(T)$ has been obtained (figure 5). If one could perform the calculation of absorption spectra $k\left(\omega^{\prime}\right)$ for different temperatures of the crystal using the kernel (5) and the appropriate form of $\gamma\left(\omega^{\prime}\right)=h / \tau\left(\omega^{\prime}\right)$ dependence, then the obtained temperature dependence of characteristic time $\tau(T)$ would have similar characters to the observed $M_{\text {eff }}(T)$ dependence. There are two circumstances for the choice of the damping of electron excitations against the spatial dispersion effects as the preferential physical model corresponding to the kernel correction in the IEs (1) or (4). First, an extremely small value of effective exciton mass $M_{\text {eff }}=5 \cdot 10^{-4} m_{\mathrm{e}}$, necessary for the only positive fundamental absorption indices $k\left(\omega^{\prime}\right)$ realization, is rather not a real one. Second, the inverse proportional dependence of the effective exciton mass upon the temperature of TGS crystal in the comparatively wide region 


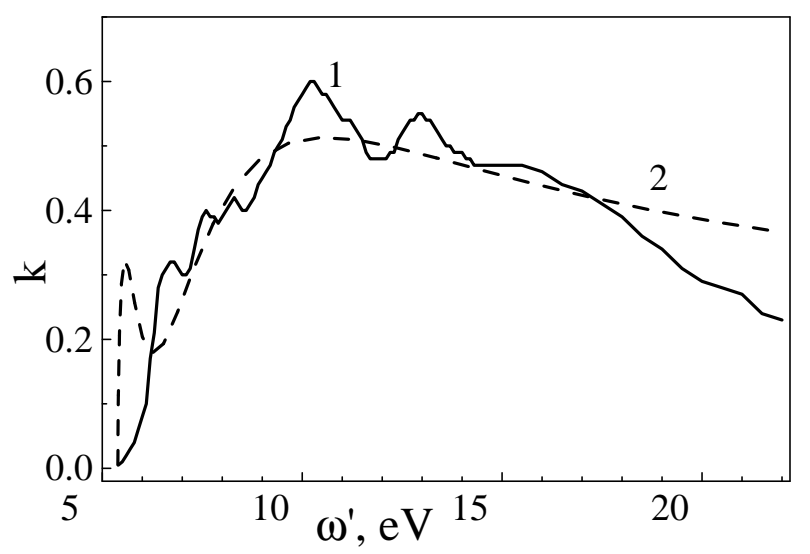

Figure 4. Absorption spectra $k\left(\omega^{\prime}\right)$ of TGS crystal at 25C: 1 - obtained from experimental reflection spectra; 2 - calculated from the IE (4) with the kernel (6)

0-79 ${ }^{\circ} \mathrm{C}$ does not coordinate with the known temperature damping of intensity of exciton fundamental absorption bands. (The infinite value of $M_{\text {eff }}$ corresponds to the absence of exciton effects). Thus, this analysis of the refractive index dispersions for different temperatures of TGS crystal makes it possible to establish the anomalous decrease of electron excitation damping time $\mathrm{t}$ in the region of $40-45^{\circ} \mathrm{C}$ of ferroelectrical phase of TGS on the ground of comparatively smooth temperature lowering of this parameter. The latter can be interpreted as an increase of electron-phonon interaction in the initial part of ferroelectrical phase $\left(T_{\mathrm{c}}<49^{\circ} \mathrm{C}\right)$ of TGS crystal.

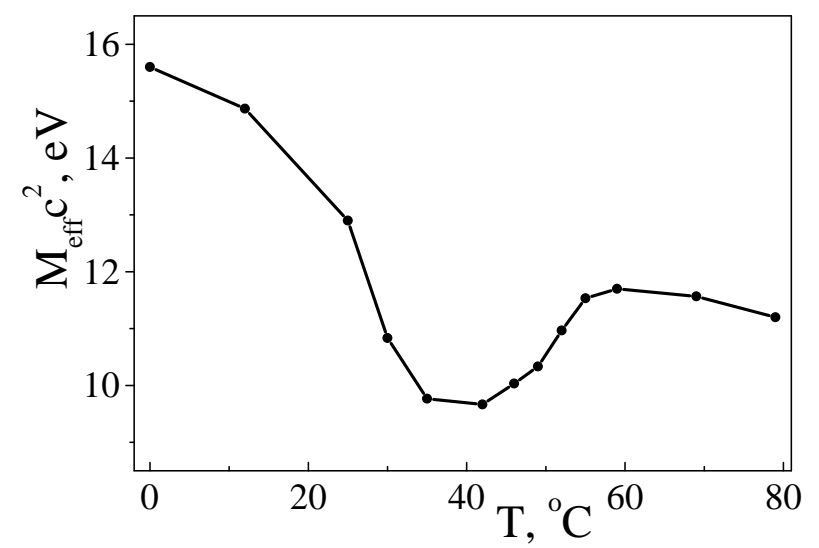

Figure 5. Temperature dependence of the effective parameter $M_{\mathrm{eff}}(T)$ for TGS crystal corresponding to the kernel (6) of IE (4)

\section{Conclusion}

1. The new calculation method of the fundamental absorption $k\left(\omega^{\prime}\right)$ spectra based on the refractive index $n(\omega)$ dispersion in the range of transparency of the 
crystalline dielectric has been worked out by solving Kramers-Kronig integral equation.

2. Negative values of absorption indices $k\left({ }^{\prime} \omega\right)$ in the narrow $(\sim 1 \mathrm{eV})$ region on the low-energy side of absorption band 5-50 eV for TGS crystal can be explained by the unaccounted electron excitation damping and/or by spatial dispersion effects. The latter factors, if taken into consideration, lead to the only positive, real $k\left(\omega^{\prime}\right)$ values and to the decrease of discrepancy between the calculated and the experimental refractive index dispersions.

\section{References}

1. Moss T.S. Optical Properties of Semiconductors, Butterworths Scientific Publ., 1959.

2. Andriyevsky B.V., Romanyuk N.A. Temperature changes of electron and phonon parameters of $\mathrm{K}_{2} \mathrm{SO}_{4}$ single crystal in the fundamental ranges of spectrum. // Optika i Spektroskopiya, 1994, vol. 76, No. 4, p. 605-608 (in Russian).

3. Andriyevsky B.V., Romanyuk M.O., Kurlyak V.Yu., Stadnyk V.Yo. New resources of the optical-refraction method for phase transition investigation in dielectrics: $\mathrm{K}_{2} \mathrm{SO}_{4}$ and $\mathrm{LiKSO}_{4}$ crystals. // Ferroelectrics, 1997, vol. 192, No. 1-4, p. 209-219.

4. Verlan' A.E., Sizikov V.S. Integral Equations: Methods, Algorithms and Programs, Naukova Dumka Publ., Kiev, 1986 (in Russian).

5. Feldman L.C., Mayer J.W. Fundamentals of Surface and Thin Film Analysis, NorthHolland Publ., New-York - Amsterdam - London, 1986.

6. Lawson C.L., Hanson R.J. Solving Least Squares Problems, Prentice-Hall Inc., Englewood Cliffs, New Jersey, 1974.

7. Romanyuk N.A., Andriyevsky B.V., Zheludev I.S. Optical properties of triglycine sulphate crystals in the 5 to $22 \mathrm{eV}$ region // Ferroelectrics, 1978, vol. 21, No. 1-4, p. 333-335.

8. Romanyuk M.O., Kostetsky O.M., Vibly V.F. Dispersion and temperature dependence of refractive indices of triglycine sulphate. // Ukrainskyj Fizychnyj Zhurnal, 1976, vol. 21, No. 2, p. 207-209 (in Ukrainian).

9. Sobolev V.V., Nemoshkalenko V.V. Methods of computational physics in the theory of solid state (Electron structure of semiconductors). "Naukova Dumka", Kiev, 1988.

10. Pekar S.I. Theory of electromagnetic waves in crystals in which excitons appear. // Zhurnal Eksperimentalnoj i Teoreticheskoj Fiziki, 1957, vol. 33, No. 4, p. 1022-1036 (in Russian).

11. Hopfield J.J., Thomas D.G. Theoretical and experimental effects of spatial dispersion on the optical properties of crystals // Phys. Rev., 1963, vol. 132, No. 2, p. 563-572.

12. Romanyuk N.A., Andriyevsky B.V., Gaba V.M. About the nature of absorption spectra of triglycine sulphate and Rochelle salt crystals at the long-wavelength edge of fundamental band. // Optika i Spektroskopiya, 1981, vol. 50, No. 1, p. 126-129 (in Russian). 


\title{
Особливості дисперсії показника заломлення в кристалах ТГC
}

\author{
О.Я.Мищишин, Б.В.Андрієвський, М.О.Романюк, \\ В.Ю.Курляк
}

Львівський державний університет ім. І.Я.Франка, 79005 Львів, вул. Кирила і Мефодія, 8

Отримано 9 вересня 1998 р., в остаточному вигляді 15 вересня 1999 р.

На основі розв'язування інтегрального рівняння Крамерса-Кроніга, яке пов'язує спектр показника заломлення $n(\omega)$ діелектрика, експериментально виміряний в області прозорості $(\omega)$, з його спектром показника поглинання $k\left(\omega^{\prime}\right)$ у фундаментальній області $\left(\omega^{\prime}\right)$, запропоновано дисперсійний аналіз цих параметрів. Розроблений метод застосовано до кристалів тригліцинсульфату, в якому встановлено прояви взаємодії валентних електронів і вивчено температурну залежність характеристичного параметра цієї взаємодії в області, що включає сегнетоелектричний фазовий перехід при $T_{\mathrm{c}}=49^{\circ} \mathrm{C}$.

Ключові слова: сегнетоелектрики, оптичні властивості, дисперсія показника заломлення

PACS: $77.80 . \mathrm{Bh}, 77.84 . \mathrm{Fa}, 78.20 . \mathrm{Ci}$ 